\title{
People will not trust unkind science
}

\section{A mean and aggressive research working culture threatens the public's respect for scientists and their expertise, says Gail Cardew.}

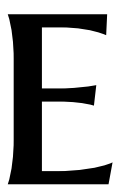
arlier this month, a survey from Wellcome in London confirmed that unkindness, and worse, is pervasive in science (see go.nature. com/2v4fn $3 w$ ). Academic leaders expressed alarm - both for the health of young researchers and for how such pressure could erode the quality of science. I think there is more to worry about.

What hope is there for those in science to build a trusting and respectful relationship with the public when so many scientists are schooled in a culture lacking these qualities?

The need for trust and respect is particularly acute now, when people, as the British politician Michael Gove infamously put it, "have had enough of experts". Similar arguments have come from around the world.

According to a 2019 report by public-opinion research firm Ipsos Mori, the way people behave, especially their ability to think of others' interests, influences their trustworthiness. Competence is not enough (go.nature. com/37lydga). This is backed up by a survey of people living on potentially contaminated land, which found that citizens who said they did not trust the underlying science were not questioning scientists' expertise, but whether scientists shared the public's interest (go.nature.com/2giuvyb).

Unkindness in science saddens me for many reasons. Obviously, I feel for the devoted researchers who began their careers expecting to revel in thejoy of discovery, only to find their love of the subject squeezed out, replaced by fear and anxiety. It also saddens me because I've witnessed some of this toxic culture spill out of the laboratory, into scientists' dealings with the public.

I have spent decades examining the relationship between science, culture and society, most recently as director of science and education at the Royal Institution of Great Britain in London, heading a team that connected leading scientists with the public - in person, online, on television and in the classroom. I have long believed that scientists have a duty to discuss their work and its implications.

Conducting research responsibly includes engaging with the public. More and more researchers are now making that effort: speaking at science festivals, giving public talks and visiting schools. They often describe not just their research, but how amazing it is to be a scientist, with the opportunity to think about the many unanswered questions facing humanity.

Most speakers take an interest in their audience and give thoughtful, sensitive answers to audience questions. But some become confrontational at any remark interpreted

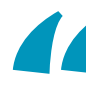

A kinder research culture will build stronger, deeper support for research."

\section{Gail Cardew is} vice-president of EuroScience, a nonprofit association of researchers, and honorary doctor of science at the University of Sussex, Brighton, UK. She is a professor of science, culture and society, formerly at Britain's Royal Institution. Twitter: @gailsci as questioning their expertise. Some dismiss questions they deem irrelevant or stupid. Some take umbrage if there are no questions, sometimes mistaking diffidence for a lack of interest. Those who do engage, but unkindly, can make matters worse. In one toe-curlingly awkward case in Europe, a speaker berated women in the audience for not asking questions. I'd bet that that audience subsequently felt less consideration both for science and for the importance of policies informed by it.

I recall how a child asked Ellen Stofan, then NASA's chief scientist, how useful Lego blocks would be to get to Mars. Stofan's warm, inspiring answer: "Everything we do at NASA, someone has to imagine first," she said. "You have to learn to be creative, to be innovative, and that's why the arts are an important part of education." I'm sure that response left her listeners with a higher esteem for science. And Fields Medal winner Cédric Villani once told me this of public engagement: “It reinvigorates you. It also helps you to understand what you are doing and why you are doing it."

Wellcome's survey found that nearly four-fifths of researchers think competition has created unkind and aggressive conditions. Most (61\%) have witnessed bullying or harassment, and $43 \%$ have experienced it themselves. Only $37 \%$ feel comfortable speaking up.

In a Nature poll following up on the survey, large majorities said that institutions, funders and lab heads should be the ones responsible for changing the culture (go.nature. com/36j4yar). If we want to build trust in science and scientists, it is not enough to think about 'what' we achieve; we must think about 'how' we influence those around us. That's why, when I left the Royal Institution, the farewell message that meant the most commended me for having achieved amazing things in a way that was "kind and humane".

A humane environment comes about through decisions, not luck. Make time for regular reflection on how you could have handled situations better, and have the courage to admit that swiftly to those concerned. Ask people for guidance, especially those supposedly less experienced, and definitely those less powerful, because they can often provide a fresh perspective. Give people time to learn and grow; recognize when they need help and also when they need to be left alone to make their own way, including mistakes. Above all, everyone should feel able to bring their whole selves to work, where differences in lives and backgrounds are celebrated, where unique perspectives and contributions are valued and not interpreted as criticism.

A kinder research culture will build stronger, deeper support for research, as well as higher-quality science. Maintaining public trust should not mean shouting more loudly in a noisy world. Instead, let's look at our own behaviour and ask ourselves - are we really acting in the best interests of others? 